\title{
AUTONOMIA, AUTODETERMINAÇÃO E INCAPACIDADE CIVIL: UMA ANÁLISE SOB A PERSPECTIVA DA BIOÉTICA E DOS DIREITOS HUMANOS
}

\author{
AUTONOMY, SELF-DETERMINATION AND CIVIL DISABILITY: \\ AN ANALYSIS UNDER THE PERSPECTIVE OF BIOETHICS AND \\ HUMAN RIGHTS
}

\author{
Rainer Grigolo de Oliveira Alves \\ Marcia Santana Fernandes \\ José Roberto Goldim
}

\section{RESUMO}

O objetivo deste artigo é estudar, com base na Bioética, nos Direitos Humanos e nas Garantias Fundamentais, a teoria da capacidade civil e sua relação com a autonomia e autodeterminação, na perspectiva da Convenção Internacional sobre os Direitos das Pessoas com Deficiência - CDPD e do Estatuto da Pessoa com Deficiência - EPD. 0 método utilizado é o qualitativo, de análise de conteúdo, em artigos científicos - originados da Filosofia, Psicologia e Psiquiatria -em textos de doutrina jurídica e a legislação nacional e internacional pertinente. Concluindo, os sistemas jurídicos que exponham a pessoa com deficiência a riscos demasiados ou que possam afetar a sua integralidade devem prever salvaguardas em conformidade com os Direitos Humanos e com os Direitos e Garantias Fundamentais.

Palavras-chaves: Bioética. Autonomia pessoal. Julgamento.

\section{ABSTRACT}

The present study deals, based on Bioethics, Human Rights and Constitutional Rights, the theory of civil capacity and its relationship with autonomy and self-determination, from the perspective of the CRPD and the EPD. The method is qualitative, of content analysis, in scientific articles - originated from 
Philosophy, Psychology and Psychiatry - texts of legal doctrine and pertinent national and international legislation. In conclusion, legal systems that expose the disabled person to too many risks or may affect their entirety should provide for safeguards in accordance with Human Rights and Constitutional Rights.

Key words: Bioethics. Personal Autonomy. Judgement.

\section{INTRODUÇÃO}

0 presente trabalho tem como objetivo identificar, sob a perspectiva dos Direitos Humanos e da Bioética, a adequação da legislação brasileira em matéria de capacidade civil, analisando, para tanto, os significados de autonomia e de autodeterminação. A perspectiva adotada será em relação à Convenção Internacional sobre os Direitos das Pessoas com Deficiência (CDPD) e seu Protocolo Facultativo, assinado em Nova York, em 30 de março de 2007, introduzido no ordenamento jurídico brasileiro via Decreto 6.949, de 25 de agosto de 2009.

O presente artigo também tem como propósito avaliar, na perspectiva da CDPD, as alterações provocadas nas regras sobre incapacidade civil introduzidas pelo Estatuto da Pessoa com Deficiência (EPD), Lei no 13.146 de 06 de julho de 2015. A Lei no 13.146/2015, em seu artigo 114, revogou o artigo $3^{\circ}$ e os incisos II e III do artigo $4^{\circ}$ do Código Civil Brasileiro (CCB), Lei 10.104/2002.

A proposta metodológica deste artigo é analisar os conceitos de autonomia e de autodeterminação, sob a ótica do Modelo de Bioética Complexa. A Bioética Complexa possibilita o enfoque interdisciplinar do tema, identificando os diferentes conceitos e, ao mesmo tempo, as intersecções das diversas ciências, envolvendo os fatos da vida e do viver humano (GOLDIM, 1997, 2006; GOLDIM, 2009).

As noções de vida e do viver se diferenciam de acordo com o significado original das palavras gregas Zoé e Bios. Zoé significava a vida em si, os aspectos biológicos de cada pessoa e do mundo que circunda. Bios, por sua vez, se referia às relações de cada um com a sociedade, ou seja, os seus aspectos biográficos (GOLDIM, 2013).

Explicamos também do ponto de vista metodológico porque utilizar o 
modelo de Bioética Complexa, como campo interdisciplinar (O’NEILL, 2002), para refletir sobre os aspectos envolvidos na temática da autonomia e da autodeterminação e sua relação com a teoria da incapacidade civil. 0 modelo de Bioética Complexa (GOLDIM, 2002, 2006) permite uma perspectiva integrada na reflexão de problemas complexos e esta perspectiva auxilia no processo de tomada de decisão envolvido em questões bioéticas, com repercussões jurídicas e em outras áreas. Os elementos básicos que devem ser incluídos neste modelo são: o problema ou conflito que desencadeia a necessidade de uma reflexão bioética; as informações, que servem para identificar os fatos e as circunstâncias envolvidas; as alternativas possíveis e as suas respectivas consequências; os referenciais teóricos e o repertório de casos que podem ampliar a compreensão das circunstâncias envolvidas, além do sistema de crenças e de afetividade (FERNANDES, 2012).

A proposta da interdisciplinaridade tem duas funções fundamentais, conforme apontado por Fernandes (2012): a primeira é ampliar os horizontes das disciplinas, ampliando os contornos limitados que cada especialidade se impõe. Esta perspectiva, no entanto, não deve ignorar o estado da arte, o conhecimento agregado ou experimentado, o contexto e os reflexos concretos do problema. 0 segundo, é a retomada de um pensamento humanista e universal, assim como proposto pelos Direitos Humanos (FERNANDES, 2012).

Os Direitos Humanos condicionam o direito ao bem estar e ao desenvolvimento pleno dos seres humanos, considerando os valores éticos; o desenvolvimento científico e tecnológico; os princípios e virtudes; o direito à identidade e o direito à saúde integral. Em 2005 a Declaração Universal sobre Bioética e Direitos Humanos (ORGANIZAÇÃO DAS NAÇÕES UNIDAS, 2005), elaborada pela UNESCO, consagrou a comunhão entre a Bioética e os Direitos Humanos, na mesma linha que já havia sido adotada na Declaração Universal sobre Genoma Humano e os Direitos Humanos (ORGANIZAÇÃO DAS NAÇÕES UNIDAS, 1997) e na Declaração Internacional sobre os Dados Genéticos Humanos (ORGANIZAÇÃO DAS NAÇÕES UNIDAS, 2004).

Portanto, a perspectiva interdisciplinar no enfrentamento de problemas complexos é uma exigência. Neste sentido, as palavras de Siebeneichler são acuradas: 
Ela [a perspectiva interdisciplinar] é, antes de tudo, uma perspectiva e uma exigência que se coloca no âmbito de um determinado tipo de processo. Ela tem a ver, basicamente, com a procura de um equilíbrio entre a análise fragmentada e a síntese simplificadora. Entre especialização e saber geral, entre o saber especializado do cientista, do expert, e o saber do filósofo (SIEBENEICHLER, 1989, p. 156).

Assim, a interface interdisciplinar da Bioética propicia a ampliação da percepção jurídica sobre temas complexos, que envolvem a vida e o viver dos seres humanos. É certo que o Direito isoladamente, ou por meio da criação de leis, não poderá compreender, avaliar ou mesmo propor soluções para estes problemas (MARTINS-COSTA; FERNANDES; GOLDIM; 2007). A atuação do Poder Legislativo está inserida em um contexto cultural (GROSSI, 2006) e pré-jurídico e conecta-se ao Direito, à Política, à Ética, entre outras disciplinas. Neste contexto, em princípio, os Direitos Fundamentais devem estabelecer os limites entre o ponderável e o imponderável na elaboração legislativa. Nesta perspectiva, a referência de Günther é bastante elucidativa:

Uma legislação que recria um determinado direito sem examinar a sua coerência com outros direitos, ou que persegue determinados objetivos políticos de modo a fazer acordos arbitrários que conduzem ao privilégio de uma posição jurídica, não trata a todos com igual consideração e respeito (GÜNTHER, 2004, p. 408).

Assim, a proposta geral deste artigo é enfrentar a coerência do Estatuto da Pessoa com Deficiência (EPD), Lei no 13.146 de 06 de julho de 2015, em particular quanto à utilização da autonomia e da autodeterminação e sua relação com a teoria das incapacidades civis, quando da falta ou redução do necessário discernimento da pessoa natural.

Observa-se que o EPD, Lei no 13.146/2015, cita a palavra autonomia onze vezes; em nenhum momento cita a palavra autodeterminação; e menciona cinco vezes a palavra vontade. Porém, em nenhum momento o EPD deixa claro em que sentido está utilizando tais palavras, o que permite múltiplas interpretações (GOLDIM, 2015).

Vejamos, a título introdutório, alguns aspectos na proposição do EPD, Lei $\mathrm{n}$ o 13.146/2015. Esta Lei foi originada do Projeto de Lei do Senado 
no 6/2003, teve tramitação preferencial sobre o projeto de lei de igual teor que tramitava na Câmara dos Deputados desde o ano 2000 (SENADO FEDERAL, 2003). O Projeto de Lei do Senado no 6/2003, aprovado no ano de 2006, seguiu para a Câmara dos Deputados, onde não teve movimentação significativa até o ano 2012, ano em que a Secretaria de Direitos Humanos - SDH sediou um grupo de trabalho para adequar o texto do PLS no 6/2003 à Convenção sobre os Direitos das Pessoas com Deficiência - CDPD (ALVES; AVILA; BRUST-RENCK, 2016). A motivação do EPD foi de conscientizar o Poder Público sobre a inclusão social da pessoa com deficiência e seus direitos à educação, à saúde, ao exercício de direitos básicos, ao trabalho, entre outros.

0 grupo de trabalho referido atuou tanto no sentido de buscar ajustar o texto à CDPD, quanto em apresentar uma proposta de substitutivo ao projeto original, Projeto de Lei 6/2003. No Projeto substitutivo passou a constar as disposições sobre a mudança no regime das incapacidades no Direito Civil brasileiro (SECRETARIA DE DIREITOS HUMANOS, 2013). Durante a votação deste substitutivo na Câmara dos Deputados no ano de 2015, foi também aprovada a inclusão da Tomada de Decisão Apoiada no texto do projeto de lei. Após, seguiu para o Senado Federal, onde foi aprovado sem modificações.

Assim, foi sancionada pela Presidente da República a Lei 13.146/2015, de 06 de julho de 2015 - a Lei de Inclusão da Pessoa com Deficiência ou, como também nomeada, o Estatuto da Pessoa com Deficiência - EPD (BRASIL, 2015). Trata-se de legislação inspirada tanto nos anseios sociais brasileiros que ensejaram o PLS 6/2003, quanto nas disposições da CDPD, com o objetivo de proporcionar e de facilitar a inclusão da pessoa com deficiência no convívio social e na cidadania, assegurando sua igualdade de direitos e liberdades fundamentais e o exercício da autonomia e da autodeterminação.

Em que pese todos os aspectos positivos proporcionados pela Lei 13.146/2015, a modificação do regime de incapacidade civil (art. 3o e $4^{\circ}$ do Código Civil Brasileiro - CCB), a partir de uma visão dicotômica entre a autonomia e a teoria das incapacidades civis, tem provocado discussões na comunidade jurídica. Quanto às modificações introduzidas pela Lei no 13.146/2015, em particular as promovidas pelo artigo 114, destaca- 
mos a que revoga o critério do necessário discernimento, por falta ou por redução, estabelecido, até então, no artigo $3^{\circ}$ e no artigo 4을 incisos II e III do Código Civil Brasileiro (CCB), Lei 10.104/2002.

0 discernimento é critério multifacetado e deve considerar a condição da pessoa de forma integrada, considerando aspectos biológicos, psiquiátricos, físicos, psicológicos, sociais e jurídicos. Este critério foi objeto de normatização, justamente porque está diretamente conectado com a autonomia e a autodeterminação dos seres humanos.

Em vista de refletir sobre os aspectos envolvidos na temática da autonomia e da autodeterminação e sua relação com a teoria da incapacidade civil no contexto do EPD, o trabalho foi divido em duas partes: na primeira são analisados os conceitos de autonomia e de autodeterminação para a Filosofia Moral kantiana, para a Psicologia Moral e para o Direito; na segunda parte, se identifica os conceitos de autonomia e de autodeterminação utilizados no artigo 12 pela CDPD, que versa sobre o exercício da legal capacity.

\section{DIVERGÊNCIAS E CONGRUÊNCIAS DOS CONCEITOS DE AUTONOMIA E DE AUTODETERMINAÇÃO}

As noções de autonomia e a autodeterminação dos seres humanos estão diretamente relacionadas aos aspectos biológicos, psicológicos e sociais dos seres humanos. Assim, a análise destas noções será estuda sob a ótica do modelo de Bioética Complexa que possibilita o enfoque interdisciplinar do tema, identificando os diferentes conceitos e, ao mesmo tempo, as intersecções das diversas ciências, envolvendo tanto a vida quanto o viver dos seres humanos (GOLDIM, 2006).

Preliminarmente, é essencial ao nosso estudo a compreensão dos conceitos extrajurídicos de autonomia e de autodeterminação e, posteriormente os conceitos jurídicos de autonomia e de autodeterminação. 


\section{CONCEITOS EXTRAJURÍDICOS DE AUTONOMIA E DE AU- TODETERMINAÇÃO}

O conceito de autonomia, do ponto de vista da filosofia moral de Kant, dever ser compreendido conjugadamente com a ideia de imperativo categórico, ou seja, não significa a liberdade de agir por mera conveniência ou egoísmo, nem mesmo significa a ação sem influência externa ou coerção (GOLDIM, 2015). Kant explica que a vontade livre é o mesmo que vontade submetida às leis morais, tendo em vista ser a liberdade uma característica inerente à vontade dos seres racionais (KANT, 2005). Kant vê a liberdade como a "chave" para explicar o que consistente a autonomia da vontade e o princípio da autonomia:

A autonomia da vontade é aquela sua propriedade, graças à qual ela é para si mesma a sua lei (independentemente da natureza dos objetos do querer). 0 princípio da autonomia é portanto: não escolher senão de modo a que as máximas da escolha estejam incluídas simultaneamente, no querer mesmo, como lei universal (KANT, 2005, p. 85).

Schneewind (2005), em razão disso, justifica que a liberdade para Kant é fundamental para a vontade autônoma. A liberdade é pressuposto da autonomia que afasta os seres racionais da atração pelo desejo e os retira do domínio da causação natural, para determinar a obrigação categórica de dizer "o que é consistente e o que é inconsistente" enquanto dever (SCHNEEWIND, 2005, p. 560).

Kant ainda afirma que a única possibilidade de definir o que realmente é bom é a partir do que ele chama de boa vontade e a relação com o conceito de autonomia:

A vontade absolutamente boa, cujo princípio tem que ser um imperativo categórico, indeterminada a respeito de todos os objetos, conterá, pois, somente a forma do querer em geral, e isto como autonomia; quer dizer: a aptidão da máxima de toda a boa vontade de se transformar a si mesma em lei universal é a única lei que a si mesma se impõe a vontade de todo o ser racional, sem supor qualquer impulso ou interesse como fundamento (KANT, 2005, p. 90-91). 
Logo, sob a perspectiva da Filosofia Moral kantiana, a autonomia é indissociável do imperativo categórico. Significa que autonomia consiste na liberdade de agir de tal modo que se possa, ao mesmo tempo, querer que esta mesma vontade seja uma lei universal (KANT, 2005).

De outro modo, a autonomia quando abordada sob a ótica da Psicologia Moral está relacionada com a capacidade para tomada de decisão em cada fase da vida humana com base em argumentos morais (GOLDIM, 2015). Jean Piaget, por exemplo, define três etapas do desenvolvimento moral conforme o grau de entendimento da regra moral em si e, com isso, possuem relação direta com a incidência da própria regra moral com o aumento e diminuição do egocentrismo e do individualismo. São elas: anomia, heteronomia e autonomia (PIAGET, 1997).

A transição entre cada fase do desenvolvimento moral humano é demonstrado por Piaget, a partir da análise do comportamento de crianças com os jogos. Na primeira fase, não há noção de regras morais, apenas de regras motoras e impulsos pelo desejo e pelo hábito. Assim, não há interação com outras crianças, nem a existência de regras coletivas. 0 jogo é totalmente individual. Já na segunda fase, ocorre o aumento do egocentrismo e a criança passa a não se preocupar com a outra que joga com ela. Durante a fase da heteronomia a criança passa a imitar o comportamento dos mais velhos. A fase da autonomia inicia com a cooperação da criança, com cooperação e consentimento mútuo quando em interação com outras pessoas. As regras morais são internalizadas e codificadas. A criança consegue decidir sobre si, tendo conhecimento do que é certo e do que é errado fazer (PIAGET, 1997).

Pode-se dizer, dessa maneira, que o ser humano é por essência biopsicossocial. Segundo Piaget, existem três dimensões que constituem o ser humano: biológica, psicológica e social, sendo que é a dimensão psicológica a moderadora entre a dimensão biológica e a dimensão social. 0 processo de assimilação das regras morais são partes de um processo de adaptação do indivíduo ao meio e de sua autorregulação com conhecimento do que é certo e do que é errado, movimentando-se entre o equilíbrio e o desequilíbrio da sua adaptação com o meio (PIAGET, 1997).

Já Kohlberg, entende que o desenvolvimento moral ocorre em três fases, sendo cada uma dessas fases subdivida em dois estágios. Nesta 
concepção, o completo desenvolvimento moral é alcançado quando a terceira fase é alcançada, chamada por ele de pós-convencional (KOHLBERG; HERSH, 2007). É quando ocorre a compreensão do contrato social e dos direitos básicos e, assim, o indivíduo age conforme as regras morais que escolheu como suas, possuindo os princípios éticos prioridade sobre a lei e sobre outras obrigações institucionais (GOLDIM, 2015).

Já Loevinger, partindo dos trabalhos de Piaget e Kohlberg, propõe uma classificação organizada em sete níveis: pré-social, impulsivo, oportunista, conformista, consciencioso, autônomo e integrado (LOEVINGER, 1966). Segundo Goldim, a classificação de desenvolvimento moral proposta por Loevinger é mais realista, uma vez que possibilita a identificação de pessoas sem autonomia, mas que mantém a capacidade de decidir preservada (GOLDIM, 2015).

Na classificação de Loevinger ficam ainda mais facilmente identificáveis as divergências e congruências conceituais sobre a autonomia na Filosofia Moral e na Psicologia Moral. 0 nível integrado proposto por Loevinger (que é superior ao nível da autonomia em sua classificação) é aquele no qual a pessoa transcende o enfrentamento de conflitos e renuncia o inalcançável, aceitando as diferenças individuais e buscando a obtenção de uma noção integrada de identidade (LOEVINGER, 1966), ou seja, corresponde a algo próximo ao que Kant define como autonomia (GOLDIM, 2015).

Outra intersecção do Filosofia Moral kantiana ocorre no desenvolvimento do Princípio da Autonomia utilizado, especialmente, na Bioética Principialista de Beuchamp e Childress, a partir da publicação da obra Principles of Biomedical Ethics, no ano de 1978 (GOLDIM, 2016). 0 conceito kantiano de autonomia foi o pressuposto que conduziu à Ética do Respeito à Pessoa, a qual, por sua vez, alcançou o status de Princípio do Respeito às Pessoa quando inserido no Relatório de Belmont, em 1978. Esse princípio apresenta dois aspectos importantes do ponto de vista ético: o primeiro refere-se ao respeito à autonomia do indivíduo, o segundo é sobre a proteção necessária àquelas pessoas que têm a autonomia diminuída (U.S. DEPARTMENT OF HEALTH \& HUMAN SERVICE, 2016). A extensão dessa proteção deve ser de tal modo que leve em consideração o risco de dano e a probabilidade do benefício (U.S. DEPARTMENT 
OF HEALTH \& HUMAN SERVICE, 2016). Em tradução livre, consta no Relatório de Belmont:

Nem todo ser humano é capaz de autodeterminação. A capacidade de autodeterminação amadurece com a vida de um indivíduo e alguns indivíduos perdem total ou parcialmente essa capacidade por causa de doença, deficiência mental, ou circunstâncias que restringem severamente a liberdade. Respeito para o imaturo e incapacitado pode exigir protegê-los conforme eles amadurecem ou enquanto eles estão incapacitados (U.S. DEPARTMENT OF HEALTH \& HUMAN SERVICE, 2016, s/p.).

Beauchamp e Childress definiram o Princípio da Autonomia a partir do Princípio do Respeito à Pessoa existente no Relatório de Belmont. Definem que uma pessoa autônoma é aquela que "age livremente de acordo com um plano escolhido para si, semelhante ao modo como um governo independente gere seus territórios e define suas políticas" (BEAUCHAMP; CHILDRESS, 2001, p. 58). Dessa maneira, o respeito à autonomia da pessoa representa reconhecer o direito dessa pessoa à opinião, a fazer escolhas e tomar decisões segundo sua vontade e crenças (BEAUCHAMP; CHILDRESS, 2001, p. 58).

Entretanto, a definição do Princípio da Autonomia utilizado por Beauchamp e Childress guarda aspecto interessante. Beauchamp publicou o texto Who desserves autonomy and who autonomy deserves respect?, no qual afirma que o princípio da autonomia utilizado na clássica obra Principles of Biomedical Ethics, na verdade, consiste no sentido de autodeterminação (BEAUCHAMP, 2000). Goldim explica que o princípio da autonomia, sob a perspectiva da Bioética, é na realidade o dever de preservar a autodeterminação, ou seja, a liberdade para tomar decisões (GOLDIM, 2015).

Judith Martins-Costa, na obra de atualização do Tomo I do Tratado de Direito Privado de Pontes de Miranda, leciona que a noção de autonomia e de autodeterminação utilizada na área da saúde, possibilita o desenvolvimento da ideia de capacidade para consentir, que apresenta uma outra esfera da capacidade civil. Dessa maneira, pode a mesma pessoa ser capaz civilmente (capacidade de fato) e incapaz para consentir e vice-versa (MARTINS-COSTA, 2009; MARTINS-COSTA, 2012, Panorama atual dos atualizadores, p. 251). 
A influência dos parâmetros médicos da Psiquiatria e da Psicologia é ainda mais ampla do que a capacidade para consentir quando pensado no desenvolvimento da Teoria das Incapacidades no Direito Civil Brasileiro. Como afirma REALE (2005), os avanços da Psiquiatria e da Psicologia foram subsídios importantes na positivação do critério do discernimento mental no regime de incapacidade civil do CCB, o que possibilitou a superação do modelo biológico da codificação civil de 1916.

\section{CONCEITOS JURÍDICOS DE AUTONOMIA E DE AUTODE- TERMINAÇÃO}

A doutrina kantiana tem relevante influência tanto na "secularização da dignidade" (SARLET, 2015, p. 295), quanto na atual concepção de dignidade resguardada e recepcionada pelo Direito: a pessoa humana é um fim em si mesmo, não um meio para alcançar outros fins, não podendo, por isso mesmo, ser admitida qualquer instrumentalização da pessoa humana (SARLET, 2015). A dignidade é "qualidade intrínseca da pessoa humana, é irrenunciável e inalienável” (SARLET, 2004, p. 42), incumbindo ao Direito garantir a sua promoção e a sua proteção, embora seja a dignidade preexistente ao Direito (SARLET, 2004).

Leonardo Agostini parte da ética kantiana para fundamentar a dignidade da pessoa humana na autonomia da vontade. Além disso, encontra fundamentos a partir da Doutrina da Virtude e da Metafísica dos Costumes para explicar que mesmo aquelas pessoas que não exercem ou não podem exercer a capacidade moral, seja por motivo de deficiência física, mental ou psicológica, não perdem sua dignidade e, por isso mesmo, continuam sendo fins em si mesmas (AGOSTINI, 2009).

Conforme define Ingo Sarlet, a dignidade da pessoa humana protegida e promovida pelo Direito está insculpida na possibilidade de autonomia (liberdade) e de autodeterminação da pessoa e de cada pessoa. Dessa maneira, a dignidade da pessoa humana não depende da realização da autonomia ou da autodeterminação, mas está na possibilidade de realização, motivo pelo qual até mesmo as pessoas absolutamente incapazes possuem exatamente a mesma medida de dignidade que qualquer 
outra pessoa humana plenamente capaz ou não. Significa afirmar que a liberdade, ou ao menos sua possibilidade (ou ainda, sua potencialidade) de liberdade protegida e promovida pelo Direito, é onde repousa a dignidade da pessoa humana (SARLET, 2004).

No âmbito do Direito Civil, fala-se em autonomia privada e também há diferenças com o conceito de autodeterminação. Para Joaquim de Sousa Ribeiro, a autodeterminação é um conceito pré-jurídico inerente à pessoa humana e aos princípios basilares do direito privado. É um conceito valor de cada indivíduo poder gerir sua vida e decidir livremente suas preferências (RIBEIRO, 2003).

Para se dizer que determinado ato teve influência da autodeterminação do sujeito, não basta a existência da possibilidade em escolher sim ou não, é preciso que tenha ocorrido a possibilidade da intervenção da personalidade civil do sujeito em controlar o ato e tomar sua decisão de forma livre e razoável. Nas palavras de Joaquim de Sousa Ribeiro:

Só pode dizer-se do ato que ele foi autodeterminado quando ao agente foi dada oportunidade efetiva de uma opção em que um dos seus termos, pelo menos, contemplava de forma tal os seus interesses que apresentava para si um suficiente conteúdo de valor (RIBEIRO, 2003, p. 43-44).

Assim, surgem dois aspectos relacionados à autodeterminação. 0 primeiro é que a autodeterminação não pode ser compreendida em abstrato, mas na consciência das escolhas e das consequências decorrentes dela (RIBEIRO, 2003). O segundo aspecto é que a autodeterminação é pressuposto do desenvolvimento da personalidade (ASCENSÃO, 2008) e, por isso, para sua existência, depende ao menos da possibilidade de ação dentro da ordem jurídica, de forma desejável, ao menos de maneira pressuposta pela ordem jurídica (standard), caso dependesse apenas de si. Uma vez que a autodeterminação é conceito pré-jurídico a única limitação existente a ela, consiste na autodeterminação de outra pessoa, quando a autodeterminação da primeira interferir na esfera particular da segunda (RIBEIRO, 2003; SILVA, 2015).

Decorrente da autodeterminação, a técnica jurídica desenvolveu o conceito de autonomia privada, o qual está delimitado por aspectos e 
disposições legais. Luís Renato Ferreira da Silva afirma que a autodeterminação é criadora de regras, podendo corresponder a outras liberdades em campos específicos do direito, por isso defende que a autonomia decorre da autodeterminação, pois é espécie de liberdade inserida no amplo conceito de autodeterminação (SILVA, 2015).

A autonomia privada para o Direito Civil consiste em "um processo de ordenação que faculta a livre constituição e modelação de relações jurídicas pelos sujeitos que nelas participam" (RIBEIRO, 2003, p. 21). Isto é, a autonomia privada está associada às relações jurídicas e à possibilidade da pessoa natural (que, por definição, também é sujeito de direitos), criar regras para si e vincular-se aos efeitos delas. É, portanto, um conceito com eficácia normativa (RIBEIRO, 2003; AMARAL NETO, 1999) diferente de decisões individuais em sentido amplo, como consiste a autodeterminação (ASCENSÃO, 2008).

Logo, a autodeterminação é gênero da qual decorre a autonomia privada. Ao mesmo tempo, espécie da autonomia privada é a liberdade contratual (SILVA, 2015). Esta, por sua vez, está relacionada às situações jurídicas que envolvam a circulação de riquezas, como a compra e venda e a liberdade para testar (SILVA, 2015), a qual dependerá, ainda, da manifestação da vontade da pessoa que exerce sua liberdade contratual.

A autonomia da vontade, outro importante conceito jurídico, é relacionada a fatores psicológicos e subjetivos que não são sinônimos de autonomia privada. Trata-se de um conceito vinculado ao individualismo que permeou as codificações civis anteriores, como é exemplo o Código Civil do Brasil de 1916, já superado pela concepção de justiça social (AMARAL NETO, 1999). Hoje, tem-se que a autonomia da vontade, quando entendida em sentido amplo, é fundamento para a liberdade enquanto garantia constitucional com fulcro na dignidade da pessoa humana.

Nota-se que os conceitos de autonomia e de autodeterminação, embora possuam pontos de intersecção conceitual, são diversos. Aqui, tais conceitos foram limitados à Filosofia Moral, à Psicologia Moral, à Bioética e ao Direito e quando aplicados de forma genérica, ou quando utilizado um conceito para interpretar o outro, provocam inúmeras deturpações no entendimento do verdadeiro significado para cada ciência. 


\section{PROTEÇÃO DA AUTONOMIA E DA AUTODETERMINAÇÃO EM MATÉRIA DE DIREITOS HUMANOS}

A Convenção sobre os Direitos da Pessoa com Deficiência (CDPD) foi a primeira convenção internacional (ou tratado internacional) a ser aprovada sob a forma do rito disposto no art. 5ํㅗ $\S 3^{\circ}$ da Constituição Federal de 1988 (CF/88). Desta maneira, possui equivalência hierárquica às emendas constitucionais, possuindo eficácia revogatória da legislação que for incompatível e já existente no ordenamento jurídico brasileiro e eficácia invalidatória das legislações posteriores a ela, que venham a dispor em contrário do seu teor (ALVES; AVILA; BRUST-RENCK, 2016).

Em razão disso, durante a tramitação do projeto de lei que resultou no Estatuto da Pessoa com Deficiência (EPD), foi organizado um grupo de trabalho para sua análise e adequação à CDPD, já incorporada ao ordenamento jurídico brasileiro. Porém, no que se refere às incapacidades civis, apresenta disposições que conflitam com a proteção almejada pela CDPD.

\section{A CONVENÇÃO SOBRE OS DIREITOS DA PESSOA COM DE- FICIÊNCIA}

A dignidade, a autonomia, a autodeterminação e a capacidade civil das pessoas são matérias que estão no âmbito internacional dos Direitos Humanos desde a Carta da ONU, em 1945. 0 mesmo ocorreu em 1948, com a Declaração Universal dos Direitos Humanos. No que se refere às pessoas com deficiência, o primeiro texto a ganhar destaque no cenário internacional foi a Declaração dos Direitos das Pessoas com Retardo Mental, de 1971. E, quatro anos depois, a Declaração dos Direitos das Pessoas Deficientes. Houve ainda, no ano de 1983, em Genebra, a Convenção no 159, da Organização Internacional do Trabalho - OIT, sobre Reabilitação Profissional e Emprego de Pessoas Deficientes. Mesmo ano em que a ONU adotou os Princípios para a Proteção das Pessoas com Doença Mental e para o Melhoramento dos Cuidados de Saúde Mental (ALVES, 2016).

Já a CDPD tem suas origens voltadas para a Conferência de Durban, no ano de 2001, quando a delegação mexicana sugeriu que fosse iniciado pro- 
cesso de negociação para elaboração de uma convenção internacional que promovesse e resguardasse os direitos humanos das pessoas com deficiência (PARADA, 2006). Essa iniciativa resultou no parágrafo 180, do Programa de Ação de Declaração de Durban, no qual a Assembleia Geral das Nações Unidas convidou que todos considerassem a possibilidade de elaborar uma convenção que, além de proteger e promover direitos das pessoas com deficiência, dispusesse contra as práticas e tratamentos discriminatórios que essas pessoas sofrem (UNITED NATIONS, World Conference..., 2016).

A Assembleia Geral das Nações Unidas também editou a Resolução 56/168 com objetivo de criar um Comitê Especial para preparar um texto prévio para o início das reuniões de negociação de elaboração da convenção (UNITED NATIONS, 2001). As reuniões do Comitê iniciaram em julho de 2002 e o texto base foi apresentado na terceira reunião, a qual ocorreu em maio de 2004 (ALVES, 2016). 0 texto final foi aprovado na oitava reunião, a qual iniciou em 14 de agosto de 2006, sendo necessária, ainda, a uniformização das terminologias empregadas às várias línguas oficiais das Nações Unidas (UNITED NATIONS, Ad Hoc..., 2016). Foi no Brasil, em 13 de dezembro de 2006, que o plenário da Assembleia Geral das Nações Unidas aprovou, por consenso, o texto que resultou na CDPD. Aberto para assinatura em março de 2007, a CDPD entrou em vigor a partir de 03 de maio de 2008 (UNITED NATIONS, Ad Hoc..., 2016).

O conceito de deficiência utilizado pela CDPD é amplo e em evolução. 0 propósito do texto é o de promover e o de assegurar direitos sociais, econômicos, culturais, civis e políticos a todas as pessoas que enfrentam barreiras sociais em razão de impedimentos de natureza física, mental, intelectual ou sensorial, que obstaculizam a participação plena e efetiva na sociedade e em igualdade de condições com as demais pessoas que não possuem deficiência (art. $1^{\circ} \stackrel{\circ}{\circ}$ CDPD).

No que se refere à autonomia e à autodeterminação em relação à capacidade civil, destaca-se o art. 12, da CDPD. Este artigo versa sobre a capacidade legal da pessoa com deficiência e teve início na preocupação de reconhecer a igualdade de direitos civis, especialmente os de liberdade e de capacidade jurídica de atuar da pessoa com deficiência. Recomendava o respeito à decisão das pessoas com deficiência e, em casos necessários, a representação legal (UNITED NATIONS, Carta..., 2016). 
As disposições do art. 12 da CDPD, quando escrito pela primeira vez em inglês, já utilizavam a expressão capacidade legal. Surgiram, a partir de então, diversas propostas de disposição legal (ALVES, 2016) e diversos questionamentos quanto ao significado de capacidade legal (ALVES, 2016; ALVES; AVILA; BRUST-RENCK, 2016). Destaca-se, neste aspecto, a posição da delegação brasileira ao concordar com a delegação costa-riquenha ao explicar que o texto pressupunha que toda pessoa possui legal capacity, embora alguns precisem de proteção ao modo como a exerce (UNITED NATIONS, 2005). A deleção brasileira ainda completou afirmando que toda pessoa com deficiência possui capacidade legal, mas que pode depender de outrem para o seu exercício (UNITED NATIONS, 2005).

A extensão do conceito de legal capacity, traduzido para o português como capacidade legal, igualmente foi objeto de discussão. 0 reconhecimento de que todas as pessoas naturais são sujeitos de direitos e que todas são capazes, não reflete as condições concretas para o exercício dessa capacidade legal - posicionamento que concordaram diversas delegações que participaram da reunião (UNITED NATIONS, 2005). Assim, após diversas sugestões, a redação final nesta matéria ficou expressa no art. 12, da CDPD da seguinte maneira:

\section{Artigo 12}

Reconhecimento igual perante a lei

1.0s Estados Partes reafirmam que as pessoas com deficiência têm o direito de ser reconhecidas em qualquer lugar como pessoas perante a lei.

2.0s Estados Partes reconhecerão que as pessoas com deficiência gozam de capacidade legal em igualdade de condições com as demais pessoas em todos os aspectos da vida.

3.0s Estados Partes tomarão medidas apropriadas para prover o acesso de pessoas com deficiência ao apoio que necessitarem no exercício de sua capacidade legal.

4.Os Estados Partes assegurarão que todas as medidas relativas ao exercício da capacidade legal incluam salvaguardas apropriadas e efetivas para prevenir abusos, em conformidade com o direito internacional dos direitos humanos. Essas salvaguardas assegurarão que as medidas relativas ao exercício da capacidade legal respeitem os direitos, a vontade e as preferências da pessoa, sejam isentas de conflito de interesses e de influência indevida, sejam proporcionais e apropriadas às circunstâncias da pessoa, se apliquem pelo período mais curto possível e sejam submetidas à revisão regular por 
uma autoridade ou órgão judiciário competente, independente e imparcial. As salvaguardas serão proporcionais ao grau em que tais medidas afetarem os direitos e interesses da pessoa.

5.0s Estados Partes, sujeitos ao disposto neste Artigo, tomarão todas as medidas apropriadas e efetivas para assegurar às pessoas com deficiência o igual direito de possuir ou herdar bens, de controlar as próprias finanças e de ter igual acesso a empréstimos bancários, hipotecas e outras formas de crédito financeiro, e assegurarão que as pessoas com deficiência não sejam arbitrariamente destituídas de seus bens.

0 artigo 12, da CDPD, não representa uma nova esfera da capacidade civil, mas dele se extrai que toda pessoa (incluindo aquelas com deficiência) possui capacidade de direito em qualquer hipótese e tem presunção da capacidade de fato - regra já prevista no Direito Civil brasileiro (ALVES, 2016). Além disso, o Direito Civil brasileiro prescreve que, quando a pessoa natural não consegue atuar pessoalmente na prática dos atos jurídicos, pode receber salvaguardas apropriadas, efetivas, proporcionais e adequadas à particularidade do caso concreto. A pessoa natural que está impossibilitada de atuar pessoalmente na prática dos atos jurídicos pode receber salvaguardas apropriadas, efetivas, proporcionais e adequadas à particularidade do caso concreto. É existente, também, no Direito Civil brasileiro, o instituto da representação legal (representação ou assistência), que atua para proteger, na medida da necessidade, os interesses dos civilmente incapazes.

No Direito Civil Brasileiro (e no Direito estrangeiro, em sua maioria), essas salvaguardas têm início com o reconhecimento da incapacidade civil. Em um primeiro momento, para anular atos jurídicos praticados sem conhecimento de causa e consequência da perda e/ou diminuição do discernimento. Em um segundo momento, para definir a curatela da pessoa reconhecida como incapaz civilmente. Essa curatela, assim como o reconhecimento da incapacidade civil, afeta tão somente a capacidade de fato, isto é, à prática pessoal dos atos da vida civil. Em nada, e em nenhuma hipótese, o reconhecimento jurídico da incapacidade civil afeta a capacidade jurídica, o reconhecimento de sujeito de direito, a personalidade civil, a pessoa natural ou normativa, a personalidade humana, a dignidade humana, nem a pessoa humana. 
Portanto, em que pese a eficácia revogatória da CDPD ao ser incorporada ao ordenamento jurídico brasileiro sob o rito do art. 5ำ, § $3^{\circ}$ da CDPD, o Direito Civil pátrio se apresentava adequado às suas disposição, no que se refere à temática de autonomia, autodeterminação e incapacidade civil. No Brasil, a incapacidade civil sempre foi exceção à regra da capacidade civil plena e nunca teve efeitos para além da capacidade de fato.

\section{O REGIME DE INCAPACIDADE CIVIL NO DIREITO BRASILEIRO}

O Código Civil Brasileiro, Lei no 10.406, de 10 de janeiro de 2002, adotou o modelo biopsicológico de incapacidade civil e, com isso, aumentou a proteção jurídica da pessoa incapaz. Afirma Miguel Reale que "após sucessivas revisões chegou-se, a final, a uma posição fundada nos subsídios mais recentes da Psiquiatria e da Psicologia" (REALE, 2005, p. 86). Subsídios encontrados a partir da positivação do discernimento mental nas causas de incapacidade civil.

Mais do que isso, a positivação do necessário discernimento representa a superação do modelo abstrato, formal e rígido do Código Civil do Brasil de 1916, por um raciocínio concreto, que tem o discernimento como eixo conceitual (MARTINS-COSTA, 2009). Com isso, foi possível a abordagem casuística da incapacidade civil a partir da graduação do regime de incapacidades a partir do grau de discernimento: incapacidade absoluta nos casos em que a pessoa tem ausência total do necessário discernimento, ou incapacidade relativa com casos em que há apenas diminuição do necessário discernimento. Isso ocorre, tendo em vista que a perda ou a diminuição do necessário discernimento resulta também na perda ou diminuição da autonomia da pessoa natural, já que ela não conseguirá criar e seguir regras para si com compreensão de causa e consequências.

Além disso, o CCB/2002 incluiu como incapacidade absoluta aquelas pessoas que não conseguem exprimir sua vontade. Trata-se de medida importante, uma vez que a pessoa que não consegue exprimir a vontade está afastada da prática de todo e qualquer ato jurídico, pois depende, impreterivelmente, da manifestação de vontade. Ademais, sua inserção 
no regime de incapacidade absoluta foi importante, pois depende da representação na prática dos atos da vida civil, pois não lhe é suficiente a figura do assistente ou representante destinada aos relativamente incapazes, já que nessa hipótese quem pratica o ato jurídico e manifesta a vontade é o próprio relativamente incapaz, assistido.

Note-se, então, que do ponto de vista amplo não se pode afirmar a existência de relação necessária entre autonomia ou autodeterminação e incapacidade civil. Ao mesmo tempo, pode-se afirmar que aquela pessoa que não tem autonomia para a prática de atos jurídicos na vida civil tem o direito de ser protegida pelo ordenamento jurídico brasileiro, enquanto pessoa humana juridicamente tutelada. Ao mesmo tempo, o Estado, enquanto órgão que emana a Lei, tem o dever de fazer constar essa possibilidade expressamente no ordenamento jurídico. Neste sentido, afirma Joaquim de Sousa Ribeiro que garantir a autonomia privada "a quem não pode exercê-la com sentido não é prestar um tributo à sua liberdade, mas antes deixar os seus legítimos interesses à mercê dos titulares de interesses contrários" (RIBEIRO, 2003, p. 41).

Porém, o EPD rompeu com a teoria das incapacidades no Direito Civil brasileiro ao retirar o necessário discernimento do texto legal e ao modificar o regime de incapacidade civil daqueles que não podem exprimir a vontade para incluí-los nas hipóteses de incapacidade relativa. Dessa maneira, o EPD criou um sistema abstrato e formal (NEVARES; SCHREIBER, 2016) no qual todas as pessoas sem discernimento são sempre capazes e, por isso, ainda que não tenham autonomia e não consigam criar regras para si e segui-las, poderão praticar todo e qualquer ato jurídico, sejam eles totalmente prejudiciais aos seus interesses ou não.

O EPD, art. 85, ainda dispõe que "a curatela afetará tão somente os atos relacionados aos direitos de natureza patrimonial e negocial”. Significa afirmar que o EPD não reconhece a existência de pessoas que, por um fato da vida humana, venham a ficar na dependência total da representação de outrem. Tais disposições são contrárias ao art. 12 da CDPD, o qual permite e reconhece a necessidade de salvaguardas apropriadas, efetivas e proporcionais à pessoa natural que está impossibilitada de exercer sua capacidade civil. 
Assim, pode-se afirmar que é salvaguarda apropriada, efetiva, proporcional e adequada oferecer assistente à pessoa natural que precisa de uma representação legal, na medida proporcional a particularidade do caso. Igualmente, é adequado permitir que a curatela também alcance atos extrapatrimoniais, quando necessário. Estas medidas estão conformes ao atual contexto jurídico, e também são adequadas no âmbito internacional dos Direitos Humanos ou no âmbito constitucional de proteção e promoção aos Direitos e Garantias Fundamentais, quando a pessoa necessita e/ou depende de outrem para a prática de todos os atos da vida civil.

\section{CONCLUSÃO}

Os significados de autonomia para a Filosofia, a Psicologia, a Psiquiatria e o Direito possuem aspectos próprios, embora em muitos aspectos possuam intersecções perceptíveis: é o caso da influência da Filosofia Moral kantiana e Psicologia Moral no Direito. 0 mesmo ocorre com a noção de autodeterminação, que possui ponto de aproximação conceitual e pontos com características próprias de cada uma das áreas referidas.

Para a Filosofia Moral kantiana, a autonomia consiste na liberdade do agir humano seja racionalmente percebida e considerada como uma lei universal o imperativo categórico. E para a Psicologia Moral e Psiquiatria a autonomia está relacionada com a capacidade para tomada de decisão em cada fase do desenvolvimento psicológico moral do ser humano.

Na perspectiva construtivista, de Piaget e Loevinger, o processo de assimilação das regras morais são partes de um processo de adaptação do indivíduo ao meio e de sua autorregulação aos valores morais reconhecidos, movimentando-se entre o equilíbrio e o desequilíbrio da sua adaptação com o meio social. 0 ser humano é por essência biopsicossocial e são três as dimensões que constituem o ser humano: biológica, psicológica e social, sendo que é a dimensão psicológica a moderadora entre a dimensão biológica e a dimensão social. E o desenvolvimento moral dos indivíduos pode ser classificado em sete níveis: pré-social, impulsivo, oportunista, conformista, consciencioso, autônomo e integrado; classificação esta que permite um reconhecimento das pessoas não autônomas. 
O Direito, igualmente, adota a noção de autonomia e autodeterminação particular. A autonomia da vontade, ou autonomia em sentido amplo é o fundamento para o tratamento da liberdade como garantia constitucional, assim como é central para o Direito Civil e o exercício das liberdades civis. A autodeterminação é inerente à pessoa humana, um conceito valor das pessoas em particular poderem gerir suas próprias vidas de acordo com suas preferências. Dela decorre a autonomia privada que, diferentemente da autonomia da vontade, é criadora de regras jurídicas que vinculam as pessoas envolvidas na relação jurídica, podendo corresponder a outras liberdades em campos específicos do Direito. Assim, a autodeterminação é gênero da qual emerge a autonomia privada.

De outra parte, pode-se afirmar que a pessoa que fica impossibilitada de exprimir a sua vontade, comprometendo o exercício de sua autonomia privada para criar regras para si, tende a ser protegida juridicamente a partir do reconhecimento da incapacidade civil. Logo, é a perda ou a diminuição da autonomia privada que conduz ao reconhecimento da incapacidade civil, não o contrário.

Reconhecer a incapacidade civil em nada afeta a autonomia da vontade, em sentido amplo, ou o direito de autodeterminação. Assim como a incapacidade civil não afeta a capacidade jurídica, a condição de sujeito ter direitos, nem a personalidade civil ou a personalidade humana, nem mesmo a dignidade e direitos fundamentais ou, ainda a esfera humana ou normativa do significado de pessoa. A incapacidade civil, no Direito Civil brasileiro, tão somente afeta o modo como os atos da vida civil são praticados ou exercidos, isto é, a capacidade de fato.

Por isso, entendemos que a redação original do CCB estava mais adequada à CDPD do que as modificações formuladas pelo EPD. Primeiro por não confundir os diversos conceitos existentes de autonomia e de autodeterminação. Segundo porque o CCB identificava claramente a relação existente entre autonomia, autodeterminação e incapacidade civil e reconhecia a incapacidade civil como protetora da autonomia para a prática de atos jurídicos na vida civil daquelas pessoas que necessitavam ser representadas ou assistidas em razão da falta ou da redução, de forma permanente ou transitória do necessário discernimento para tomada de decisão em seu próprio benefício. É importante destacar que o CCB não 
tratava a incapacidade civil como pressuposto da perda ou diminuição da autonomia.

As pessoas que não possuem o necessário discernimento, ou que o tem diminuído, precisam de salvaguardas apropriadas, efetivas, adequadas e proporcionais - nos termos da CDPD à sua situação fática. 0 mesmo ocorre com aquelas pessoas que não podem ou não conseguem exprimir a vontade. De nada adianta oferecer um assistente para que a pessoa possa exprimir a sua vontade se em razão de um fato da vida humana ela não pode fazê-lo.

A Lei não pode alterar fatos, ou mesmo a realidade. Vejamos algumas situações como exemplo: a pessoa em estado de coma ou em estado de vigília, não tem condições de praticar atos jurídicos pessoalmente, com apenas a assistência de outrem, por imposição da Lei; a pessoa sem discernimento mental ou com doença mental grave, ou ainda com déficit intelectual severo, não terá compreensão das causas e das consequências de seus atos ou atos de outrem, em seu benefício ou prejuízo em razão da mudança legislativa. As pessoas nestas circunstâncias necessitam de ajuda, necessitam ser representadas por pessoas que possam falar em seu benefício.

A CDPD não vetou, ressalta-se, a possibilidade do reconhecimento de uma incapacidade civil absoluta e da representação legal e partir da definição de uma curatela para todos os atos. Pelo contrário, o que a CDPD faz é colocar como regra a presunção da plena capacidade civil das pessoas e em exceção as salvaguardas que devem ser analisadas caso a caso, evitando prejuízos para mais ou para menos. 0 que se deve lembrar é que a CDPD tem alcance internacional e suas disposições têm o objetivo de englobar diversos cenários jurídicos.

No Brasil, a capacidade legal não representa uma nova esfera da capacidade civil, mas uma regra hermenêutica já existente no desenvolvimento da Teoria das Incapacidades: a incapacidade civil afeta tão somente a capacidade de fato e, mais do que isso, todas as pessoas que atingiram a maioridade tem presunção da plena capacidade em igualdade de condições com qualquer outra.

Por fim, os sistemas jurídicos devem ser estabelecidos em vista a promover a proteção do ser humano e suas vulnerabilidades, estes sis- 
temas não podem expor a pessoa natural. Em particular as pessoas com discernimento mental reduzido ou inexistente, a riscos demasiados que possam afetar a sua integralidade psíquica, física, moral e sociais, por isso salvaguardas devem ser previstas em conformidade com os Direitos Humanos e com os Direitos e Garantias Fundamentais.

\section{REFERÊNCIAS}

AGOSTINI, Leonardo. Autonomia: fundamento da dignidade humana em Kant. Dissertação de mestrado. Porto Alegre: PUCRS, 2009.

ALVES, Rainer Grigolo de Oliveira. A teoria da incapacidade civil no direito brasileiro: avanços e retrocessos relacionados ao discernimento mental. Porto Alegre: Dissertação. Centro Universitário Ritter dos Reis, 2016.

. AVILA, Ana Paula de Oliveira; BRUST-RENCK, Priscila Goergen. Os Direitos Humanos e o Direito Civil: diretivas da convenção da ONU sobre os direitos das pessoas com deficiência para um regime inclusivo de capacidade civil. Revista da AJURIS, v. 43, n. 141, p. 235-264, dez.2016.

AMARAL NETO, Francisco dos Santos. Autonomia Privada. Revista CEJ, v. 3, n. 9 , set./dez.1999, Disponível em: <http://www.cjf.jus.br/ojs2/index.php/revcej/ article/viewArticle/235/397>. Acesso em: 12 nov. 2016.

ASCENSÃO, José Oliveira. A dignidade da pessoa e o fundamento dos direitos humanos. Revista da Faculdade de Direito da Universidade de São Paulo, v. 103, p. 277-299, jan./dez.2008.

BEAUCHAMP, Tom L.; CHILDRESS, James F. Principles of Biomedical Ethics. 5. ed. New York: Oxford, 2001.

. Who deserves autonomy and who autonomy desserves respect? In: Tom L. Beauchamp (ed.). Standing on principles: collected essays. New York: Oxford University Press, p. 79-100, 2000.

BRASIL. Lei no 13.146, de 06 de julho de 2015 - Institui a Lei Brasileira de Inclusão da Pessoa com Deficiência (Estatuto da Pessoa com Deficiência). Brasil: DF. Disponível em: < http://www.planalto.gov.br/ccivil_03/_ato2015-2018/2015/ Lei/L13146.htm>. Acesso em: 20 abr. 2016. 
FERNANDES, Márcia Santana. Bioética, Medicina e Direito de Propriedade Intelectual: Relação entre patentes e células-tronco humanas, São Paulo: Editora Saraiva, 2012.

GOLDIM, José Roberto. Autonomia e autodeterminação: confusões e ambiguidades. In: Judith Martins-Costa (coord). Conversa sobre autonomia privada. Canela: IEC, 2015.

. Belmont Report. Disponível em: https://www.ufrgs.br/bioetica/belmont. htm. Acesso em: 07 nov. 2016.

Bioética: o tempo da vida e do viver. Palestra proferida na Jornada da Sociedade de Psicologia do Rio Grande do Sul. Porto Alegre, 08 de junho de 2013.

. Bioética complexa: uma abordagem abrangente para o processo de tomada de decisão. Revista da AMRIGS, Seção Bioética, v.53, n.1, p.58-63, 2009.

. Bioética: origens e complexidade. Revista HCPA, v. 26, n. 2, p. 86-92, 2006.

Bioética e interdisciplinaridade. Educação, Subjetividade \& Poder, Porto Alegre, v. 4, p. 24-28, 1997.

. 0 consentimento informado numa perspectiva além da autonomia. Revista da Amrigs, Porto Alegre, v. 46, n. 3-4, p.109-116, jul./dez. 2002.

GROSSI, Paolo. História da Propriedade e Outros Ensaios. Rio de Janeiro: Renovar, 2006.

Primeiras Lições Sobre Direito. São Paulo: Editora Forense, 2006.

GÜNTHER, K. Teoria da argumentação no direito e na moral: justificação e aplicação. São Paulo: Landy, 2004.

MARTINS-COSTA, Judith. Capacidade para consentir e esterilização de mulheres tornadas incapazes pelo uso de drogas: notas para uma aproximação entre a técnica jurídica e a reflexão bioética. In: Judith Martins-Costa; Letícia Ludwing Möller (Org.). Bioética e responsabilidade. Rio de Janeiro: Forense, p. 299346, 2009. 
; FERNANDES, Marcia Santana Fernandes; GOLDIM, José Roberto. Lei de biossegurança: revisitando a medusa legislativa. In: NICOLAU JUNIOR, M. (Ed.). Novos direitos. Paraná: Juruá, p. 233-246, 2007.

- Panorama atual pelos Atualizadores. In: PONTES de MIRANDA, Francisco Cavalcanti. Tratado de Direito Privado - Tomo I. São Paulo: Revista dos Tribunais, 2012.

KANT, Immanuel. Fundamentação da metafísica dos costumes. Lisboa: Edições 70, 2005.

KOHLBERG, Lawrence; HERSH, Richard H. Moral Development : A Review of the Theory. Theory into practice, v. 16, n. 2, p. 53-59, 2007.

LOEVINGER, Jane. The meaning and measurement of ego development. American Psychologist, v. 21, n. 3, p. 195-206, 1966.

NEVARES, Ana Luiza Maia; SCHREIBER, Anderson. Do sujeito à pessoa: uma análise da incapacidade civil. Quaestio iuris, v. 9, n. 3, p. 1545-1558, 2016.

O'NEILL, Onora. Autonomy and trust in bioethics. Cambridge: Cambridge University, 2002.

ORGANIZAÇÃO DAS NAÇÕES UNIDAS - ONU. UNESCO. DECLARAÇÃO INTERNACIONAL SOBRE OS DADOS GENÉTICOS HUMANOS, Genebra, 2004.

. UNESCO. Declaração Universal sobre Bioética e Direitos Humanos. Genebra, 2005.

. UNESCO. Declaração Universal sobre Genoma Humano e dos Direitos Humanos. Genebra, 1997.

PARADA, Berenice Díaz Ceballos. Iniciativa mexicana para la elaboración de una convención internacional de las Naciones Unidas para la promoción de los derechos de las personas con discapacidad. Revista Mexicana de Política Exterior, v. 78, p. 169-216, 2006.

PIAGET, Jean. The Moral Judgment of the Child. Glencoe, Illinois: The Free Press, 1997. 
REALE, Miguel. História do novo Código Civil. São Paulo: Revista dos Tribunais, 2005.

RIBEIRO, Joaquim de Sousa. 0 problema do contrato: as cláusulas contratuais gerais e o princípio da liberdade contratual. Coimbra: Almedina, 2003.

SARLET, Ingo Wolfgang. Dignidade da pessoa humana e direitos fundamentais na Constituição da República de 1988. 3. ed. Porto Alegre: Livraria do Advogado, 2004.

Notas sobre a dignidade (da pessoa) humana no âmbito da evolução do pensamento ocidental. In: Draiton Gonzaga de Souza; Francisco Jozivan Guedes de Lima (orgs.). Filosofia e Interdisciplinaridade. Porto Alegre: Editora Fi, 2015.

SCHNEEWIND, Jerome B. A invenção da autonomia: uma história da filosofia moral moderna. São Leopoldo: Editora Unisinos, 2005.

SECRETARIA DE DIREITOS HUMANOS. Estatuto da pessoa com deficiência: proposta de substitutivo. 2013. Disponível em: <http://www.pessoacomdeficiencia.gov.br/app/sites/default/files/arquivos/\%5Bfield_generico_imagensfilefield-description\%5D_93.pdf>. Acesso em: 29 jan. 2016.

SENADO FEDERAL. Projeto de Lei do Senado no 6, de 2003. Brasil: DF. Disponível em: <http://www25.senado.leg.br/web/atividade/materias/-/materia/54729>. Acesso em: 04 fev. 2016.

SIEBENEICHLER, Flávio B. Encontros e desencontros no caminho da interdisciplinaridade: G. Gusdorf e J. Habermas. Revista Tempos Brasileiros: Jürgen Habermas: 60 anos, Rio de Janeiro, v. 98, p.153-180, jul./set. 1989.

SILVA, Luis Renato Ferreira da. Autonomia Privada e usos negociais empresariais. In: Judith Martins-Costa (coord.), Conversas sobre autonomia privada. Canela: IEC, 2015. p. 21-34.

UNITED NATIONS. 56/168. Comprehensive and integral international convention to promote and protect the rights and dignity of persons with disabilities. 2001. Disponível em: <http://www.un.org/esa/socdev/enable/disA56168e1. htm>. Acesso em: 26 jun. 2016. 
Ad Hoc Committee on a Comprehensive and Integral International Convention on the Protection and Promotion of the Rights and Dignity of Persons with Disabilities. Disponível em: <https://www.un.org/development/ desa/disabilities/resources/ad-hoc-committee-on-a-comprehensive-andintegral-international-convention-on-the-protection-and-promotion-of-therights-and-dignity-of-persons-with-disabilities.html>. Acesso em: 26 jun. 2016.

. Carta de fecha 11 de julio de 2002 dirigida al Secretario General por el Representante Permanente de México ante las Naciones Unidas. Disponível em: <http://www4.congreso.gob.pe/comisiones/2002/discapacidad/ convencion/N0247986.pdf>. Acesso em: 27 jun. 2016.

Daily summary of discussion at the fifth session 25 January 2005. 2005. Disponível em: <http://www.un.org/esa/socdev/enable/rights/ahc5sum25jan.htm>. Acesso em: 4 fev. 2016.

. World Conference against Racism, Racial Discrimination, Xenophobia and Related Intolerance. Disponível em: <http://www.un.org/WCAR/durban. pdf>. Acesso em: 26 jun. 2016.

U.S. DEPARTMENT OF HEALTH \& HUMAN SERVICE. The Belmont Report. Disponível em: <http://www.hhs.gov/ohrp/regulations-and-policy/belmontreport/index.html>. Acesso em 10 nov. 2016.

Recebido em: 13-11-2017

Aprovado em: 31-1-2018

\section{Rainer Grigolo de Oliveira Alves}

Advogado. Mestre em Direito com área de concentração em Direitos Humanos. Pesquisador do Laboratório de Pesquisa em Bioética e Ética na Ciência do Hospital de Clínicas de Porto Alegre (LAPEBEC/HCPA). E-mail: rainergrigolo@hotmail.com

Ávila e Grigolo Advogados Associados.

Avenida Benjamin Constant - de 1303 ao fim - lado ímpar, São Geraldo, 90550005 - Porto Alegre, RS - Brasil 


\section{Marcia Santana Fernandes}

Doutora em Direito. Pesquisadora em nível de Pós-Doutorado do Programa de Pós-Graduação em Direito da PUCRS. Pesquisadora do Laboratório de Pesquisa em Bioética e Ética na Ciência- LAPEBEC/HCPA. Coordenadora do Núcleo de Estudos em Direito, Saúde e Bioética da Escola Superior de Magistratura ESM/AJURIS - RGS. Professora Permanente do Mestrado Profissional em Pesquisa Clínica do HCPA. Membro associado e do Conselho do Instituto de Estudos Culturalistas - IEC. E-mail: msfernandes@hcpa.edu.br

Hospital de Clínicas de Porto Alegre, Laboratório de Pesquisa em Bioética e Ética na Ciência LAPEBEC e NEPTA. Rua Ramiro Barcelos 2350, Santana, 90035903 - Porto Alegre, RS - Brasil

\section{José Roberto Goldim}

Doutor em Medicina. Biólogo. Chefe do Serviço de Bioética do Hospital de Clínicas de Porto Alegre (HCPA). Coordenador e pesquisador responsável pelo Laboratório de Pesquisa em Bioética e Ética na Ciência- LAPEBEC/HCPA. Professor da Faculdade de Medicina e do PPG/ Ciências Médicas da UFRGS. Professor de Graduação e Pós-Graduação stricto e lato sensu da PUCRS. E-mail: jgoldim@hcpa.edu.br

Hospital de Clínicas de Porto Alegre, Grupo de Pesquisa e Pós-Graduação. Ramiro Barcellos 2350, Bom Fim, 90035903 - Porto Alegre, RS - Brasil 